\title{
Coronary sinus Ostial atresia with a window to the left atrium and persistent left superior vena cava in an adult patient
}

\author{
Jing $\mathrm{Li}^{1}$ and Xiaoyun Wang ${ }^{2}$ \\ ${ }^{1}$ Zhejiang University School of Medicine Second Affiliated Hospital \\ ${ }^{2}$ Affiliation not available
}

June 1, 2021

\begin{abstract}
Coronary sinus Ostial atresia(CSOA) is a rare cardiac malformation. The morbidity rate is $0.1 \%(1)$. We report here on a rare case of an incidentally found CSOA with unroofed coronary sinus(UCS) and persistent left superior vena cava(PLSVC) in an adult patient. Diagnostic methods included echocardiography, multidetector row computed tomography.
\end{abstract}

\section{CASE REPORT}

Coronary sinus ostial atresia with a window to the left atrium and persistent left superior vena cava in an adult patient

Jing Li MD ${ }^{1}$, Xiaoyun Wang MD²

${ }^{1}$ Department of Gynecology, The Second Affiliated Hospital of Zhejiang University School of Medicine, Hangzhou 310009, Zhejiang Province, China

${ }^{2}$ Cardiovascular Department, The Second Affiliated Hospital of Zhejiang University School of Medicine, Hangzhou 310009, China

Correspondence

Xiaoyun Wang, Department of Gynecology, The Second Affiliated Hospital of Zhejiang University School of Medicine, 88 Jiefang Road, Hangzhou 310009, Zhejiang Province, China. doctorwangxy@zju.edu.cn

\begin{abstract}
Coronary sinus ostial atresia(CSOA) is a rare cardiac malformation. The morbidity rate is $0.1 \% .{ }^{1}$ We report here on a rare case of an incidentally found CSOA with unroofed coronary sinus(UCS) and persistent left superior vena cava(PLSVC) in an adult patient. Diagnostic methods included echocardiography, multidetector row computed tomography.
\end{abstract}

\section{KEYWORDS}

congenital heart disease, coronary sinus, unroofed coronary sinus, persistent left superior vena cava,echocardiography

\section{INTRODUCTION}

Congenital anomalies of the coronary sinus(CS)are rare, but well-documented findings, including persistent left superior vena, unroofed coronary sinus and coronary sinus ostial atresia. We present a case of CSOA with PLSVC. 


\section{CASE REPORT}

A 36-year-old woman presented to the local hospital due to left abdominal pain. The pain was persistent and can't be relieved. She had vomited twice without fever and regurgitation of sourness. The X-Ray revealed that there was incomplete intestinal obstruction. There was not significant relief after the tratements of herb retention enema, anti-infection and fluid infusion, so she presented to our hospital for further tratements. She had a temperature of 38.1 degrees celsius without shivering.

She knew that she had a congenital heart disease without the definite diagnosis when she was ten years old. she had occasional chest pain after 30-years old. Two months ago, the right extremities were numb, powerless, and the right eye was amaurotic. She had been constipated for two months. She had a cesarean section in 2009.

Transthoracic echocardiography revealed that there is a large cyst with many septums, which connected with the left atrium. The connection diameter is 2.2 centimetres. Color Doppler showed the flow converged between left atrium and the cysts. Due to the cysts' irregular shape and large volume, it couldn't be detected in a view (Figure 1). There was also PLSVC connecting to the left atrium(LA). Retrograde flow from the LA to PLSVC acrossing the bridging innominate vein to the right superior vena cava(RSVC) was found. Suprasternal notch view revealed that the PLSVC with retrograde flow drained into bridging innominate vein (Figure 2). In agitated saline contrast echocardiography, the right atrium (RA) and right ventricle(RV) was filled with air bubbles, but not the cysts and left atrium. This finding demonstrated that the PLSVC didn't connect to right atrium directly or through the CS. And In contrast-enhanced echocardiography of the left heart (including left ventricular opacification [LVO]), an ultrasound contrast agent filled the cysts and LA with some area filling-defect was observed,some was slow,in a swirl-like shape (Figure 1). Slow hemodynamics is a risk factor for thrombosis.

The multi-slice spiral CT showed that there was a huge dilated CS. The dilated CS was separated in many cysts(composed of the great and small cardiac veins). The CS was ended in a long blind pouch with atresia of its ostium. There was an UCS about $2.4 \mathrm{~cm}$ as an outlet for the dilated CS. PLSVC connecting to LA and draining into the bridging innominate vein was observed (Figure 3). The three-dimensional reconstruction CT shows the whole morphology in cardiac anomaly (Figure 4).

According to all above, we considered that she had CSOA, the dilated CS drained into the LA through UCS, which was as a window to the left atrium for all cardiac vein to return. A PLSVC connecting to left atrium with retrograde flow drained into bridging innominate vein.

\section{DISCUSSION}

The CS is located posteriorly in the left atrioventricular groove. It opens into the RA through the orifice, which is located in the posterior and inferior wall of the RA and superior to the tricuspid valve. The dilation of CS is an important sign of many cardiac anomalies, such as PLSVC, UCS, Partial anomalous pulmonary venous return, coronary arterio-venous fistula, elevated right atrial pressure. CSOA is a rarely anomaly with a prevalence of about $0.1 \%$. There are three types of cardiac venous drainage in patients with CSOA. Type (A): A PLSVC connected to the CS. Type (B): Venous drainage through the UCS to the LA. Type (C): Anomalous CS drainage (asterisk) into the RA through an accessory vein, such as a small cardiac vein or a Thebesian vein. ${ }^{2}$ This case belongs to the type B. A PLSVC results from persistent patency of the left anterior cardinal vein draining into a dilated coronary sinus. PLSVC is the most common congenital thoracic venous anomaly with a prevalence of $0.3-0.5 \%$ in general population. ${ }^{3}$ Almost $40 \%$ of patients with PLSVC can have a variety of associated cardiac anomalies. CSOA with a PLSVC drained into left atrium is a rare cardiac anomaly. ${ }^{4}$ In this case, the patient had a extremely dilated coronary sinus with an irregular shape, the LA was the only alternative pathway of the dilated CS, ${ }^{5,6}$ and the PLSVC connected to the LA with retrograde flow, which was ignored probably in transthoracic echocardiography. The dilated CS was so large with irregular shape, there was the probability of some tiny thrombus in it causing embolism in any vessel. This patient has a renal infarction, the source of the embolus is most likely from the dilated CS and LA. In the presence of a left persistent vena cava with a relatively normal diameter innominate vein, CSOA 
via retrograde drainage should be suspected. Multimodality imaging such as, transthoracic echocardiography, transesophageal echocardiography, contrast echocardiography, three-dimensional echocardiography, CT, or magnetic resonance imaging is needed to diagnose this anomaly. It is imperative to identify this anomaly preoperatively because ligation of PLSVC can lead to interruption of coronary venous flow and, subsequently, myocardial congestion and ischemia. ${ }^{7-10}$ The relationship between CSOA plus LSVC and other cardiac anomalies is unclear. Other cardiac malformations coexist in approximately $56 \%$ of reported cases. ${ }^{11}$ This patient had no other cardiac anomalies, so she only accept anticoagulant therapy. She has now been discharged from the hospital and receives regular follow- up care.

\section{CONFLICT OF INTEREST}

The authors have no conflicts of interest to declare.

\section{REFERENCES}

1. Fujibayashi K, Saeki Y, Sawaguchi J, et al. A case of cardiac resynchronization therapy in a patient with coronary sinus ostial atresia and persistent left superior vena cava[J]. Journal of Cardiology Cases, 2020, 21( 3):101-103.

2. Weng S, Tang M, Zhou B, et al. Supraventricular tachycardia in patients with coronary sinus stenosis/atresia: Prevalence, anatomical features, and ablation outcomes. J Cardiovasc Electrophysiol. 2020, 31(12):3223-3231.

3. Gustapane S, Leombroni M, Khalil A, et al. Systematic review and meta-analysis of persistent left superior vena cava on prenatal ultrasound: associated anomalies, diagnostic accuracy and postnatal outcome. Ultrasound Obstet Gynecol. 2016, 48(6):701-708.

4. Kwon SH, Oh JH. Coronary sinus orifice atresia with a persistent left superior vena cava and an aberrant communicating vein into the right atrium in an adult patient. Clin Radiol. 2011, 66(1):93-95.

5. Shum JS, Kim SM, Choe YH. Multidetector CT and MRI of ostial atresia of the coronary sinus, associated collateral venous pathways and cardiac anomalies. Clin Radiol. 2012, 67(12):e47-52.

6. Hiroshima KI, Goya M, Nagashima M, et al. Ostial atresia of the coronary sinus in patients with supraventricular arrhythmias. J Arrhythm. 2019, 35(3):554-557.

7. Fulton JO, Mas C, Brizard CP, et al. The surgical importance of coronary sinus orifice atresia. Ann Thorac Surg. 1998, 66(6):2112-2114.

8. Petit CJ, Webb GD, Rome JJ. Creation of a coronary sinus to atrial communication in coronary sinus ostial atresia improves cardiac function after Fontan. Catheter Cardiovasc Interv. 2007, 70(6):897-899.

9. Jha NK, Gogna A, Tan TH, et al. Atresia of coronary sinus ostium with retrograde drainage via persistent left superior vena cava. Ann Thorac Surg. 2003, 76(6):2091-2092.

10. Ayhan, evik, Murat, et al. Coronary sinus ostial atresia: A rare associated anomaly that should be remembered in patients undergoing univentricular palliation. Anatolian journal of cardiology, 2018, 20(5):303-304.

11. Santoscoy R, Walters H L, Ross R D, et al. Coronary sinus ostial atresia with persistent left superior vena cava. Annals of Thoracic Surgery, 1996, 61(3):879-882.

\section{Hosted file}

IMAGES.pptx available at https://authorea.com/users/417389/articles/524519-coronary-sinusostial-atresia-with-a-window-to-the-left-atrium-and-persistent-left-superior-vena-cavain-an-adult-patient 